\title{
Investigation on People's Awareness of Kitchen Waste Related Issues in Hangzhou, China
}

\author{
Xiao-Lu XU ${ }^{1, a}$, De-Yong ZHANG ${ }^{1, b,{ }^{*}}$ and Xiu-Ying SHEN ${ }^{2, c}$ \\ ${ }^{1}$ Zhejiang Shuren University, Shuren Road 8, Hanghzou, China \\ ${ }^{2}$ Zhejiang Universities of Science and Technology, Liuhe Road 318, Hanghzou, China \\ axxlhz2008@163.com, bdeyonghz@163.com, 'sxying01@163.com \\ ${ }^{*}$ Corresponding author
}

Keywords: Kitchen waste, Questionnaire, Garbage classification, Garbage disposal

\begin{abstract}
In order to analyze the common people's understanding and altitude about kitchen waste related issues, 4 questionnaires with totally 55 questions were designed and investigated in Hangzhou during 2014 to 2016. Fourteen core questions summarized from the questionnaires, as well as the corresponding responses were presented and discussed here. Investigation in common people showed that they paid less attention to kitchen waste related problems than those employed in food industry. Most people get knowledge of kitchen waste via such modern media as TV or internet. Investigations in catering industry showed that the recycling of kitchen waste was still poorly understood and conducted. The awareness of environmental protection in people was related to their certain work position even in catering industry. Garbage classification has not been conducted ideally in Hangzhou. Most people believed that they are willing to cooperate to improve disposal of kitchen waste, while it seemed not so easy to put it into action because of tedious daily operations. It is necessary for the government to make more operational measures.
\end{abstract}

\section{Introduction}

Kitchen waste refers to the garbage produced by residents' daily living and food processing, professional catering services, catering activities in enterprises \& institutions, and other activities related to foods. Kitchen waste contains very high moisture and organic matter, which is easy to rot and produce malodor. However, after proper treatment and processing, it can be converted into valuable resources [1-3]. Cities around the world are all being challenged by domestic waste [3-5]. In 2010, the government of Hangzhou promoted experimental project of garbage classification. Garbage was asked to be divided into recyclable waste, kitchen waste, hazardous waste and other garbage. As the government's promotion of garbage management, the kitchen waste produced by most large restaurants and enterprises in Hangzhou was treated by appointed transportation enterprise for standardized disposal. While, for ordinary households with less daily production, kitchen waste is usually mixed with ordinary domestic waste, and then landfill treatment. Statistics in 2014 showed that the total amount of kitchen waste collected in the main urban area of Hangzhou was 131.4 thousand tons, meanly 360 tons per day. The average proportion of kitchen waste in the garbage collected with classification in Hangzhou was 53.41\%. The collected domestic garbage with classification (including classified kitchen waste and other garbage) accounted for only 9.71-28.39\%, averagely $18.79 \%$ [6]. Namely, a large quantity of waste was being collected without classification. The reason was related to the poor public awareness in people and the garbage disposal without adequate classification. Overall, the achievement of garbage-classification project promoted by the government was still unsatisfactory.

Currently, urbanization is developing rapidly in China, and most governors are being challenged by kitchen waste which is growing rapidly too. Solution to the problem of excessive kitchen waste requires deep investigation, scientific measures and efficient operation. Anyway, it is certain that cooperation by general citizens is necessary for the government to solve the problem of kitchen waste finally. Therefore, an investigation of public awareness of kitchen waste issues is of great importance for determination of policy and measures. 


\section{Respondents of the Investigation}

The investigations were conducted in the urban region of Hangzhou. Four kinds of career fields were involved in the investigations: food processing enterprises, enterprises \& institutions canteens, small restaurants and ordinary residents. The age of the survey subjects was divided into three groups: young age (18-40), middle age (40-60), and old age (60-).

\section{Questionnaire Design}

In consideration of different populations, 4 questionnaires with totally 55 questions were designed. The investigations were conducted in the urban region of Hangzhou during 2014 and 2016. Core topics are mainly related to production and disposal of kitchen waste, awareness of environmental protection, proposals about garbage disposal, etc. A total of 2000 questionnaires were distributed, and 1868 valid answer sheets in them were recovered. Therefore, an effective recovery rate of $93.4 \%$ was got. For the convenience of discussion, details in the large scale of questionnaires was omitted and only 14 core questions were summarized and presented here (Table 1).

\section{Main Observations}

Table 1 main observation in the investigations

Questions
1, Do you think it is really necessary
to classify kitchen waste from other
waste in Hangzhou currently?

2, Generally, how do you treat the kitchen waste in your home?

3, Do you know the interim management of food waste disposal by government in Hangzhou?

4. Have you ever received similar publicity and education?

5 , Do you think garbage classification is really beding implemented at present?

6, How do you usually get such knowledge as the hazards of kitchen waste, disposal methods of it, and garbage related laws \& regulations?

7, Can kitchen waste be separated into recyclable refuse and refuse can not be recycled? Is it necessary?

\section{Answers}

$68 \%$ respondents thought it is necessary. $20 \%$ thought it is unnecessary. $12 \%$ are uncertain. (Note: $81 \%$ of those people who think it is necessary have education experience not less than high school. Those with lower educational background generally do not care about this problem.) $62 \%$ respondents put them into special trash can for classificaiton. 23\% respondents have no special trash can for kitchen waste. $14 \%$ semi-classify their waste. $1 \%$ respondents transfer their waste into treasure.

$16 \%$ respondents know. 84\% respondents do not know.

28\% respondents have. $72 \%$ respondents have not.

$20 \%$ respondents think it is. 80 respondents do not think so. (Note: Only a small percentage of the population said they had heard about it but did not understand it, while $87 \%$ of the population had a college degree or above) $49 \%$ respondents through broadcasting, internet or television. $31 \%$ respondents through newspapers or magazines. $20 \%$ respondents through publicity windows.

$13 \%$ respondents think it is possible and necessary. $31 \%$ respondents think it is generally impossible to distinguish completely. 31\% respondents think it is impossible and unnecessary. $15 \%$ respondents think it is possible but unnecessary. (Note: Food and beverage management posts are in the majority among those who think it is possible and necessary, and those who think it is impossible and unnecessary are in the majority of the general catering posts.) 
8, Do you think kitchen waste is a resource that can be fully recycled? 9 , How often do you deal with kitchen waste?

10, How does your unit classify food waste?

11, What do you think are the main difficulties in the implementation of kitchen waste recycling?

12, What kind of trouble do you think the improper disposal of kitchen waste will bring to our life? (multiple selection)

13, What do you think is the most important problem in garbage management?

14, What should be done to improve the efficiency of classification of food related garbage?
$35 \%$ respondents considered feasible; $15.8 \%$ respondents holding negative opinions; 49\% respondentsr eservations. $65 \%$ respondents does once a day. $25 \%$ respondents does once every three days. $8 \%$ respondents does once every week. $2 \%$ respondents does less than 1 times each week. $44 \%$ respondents put all the garbage together. 29\% respondents separate solid food waste from the liquids. $21 \%$ respondents use different plastic barrels for different garbage. 6\% respondents use a trash can with a filter membrane to separate different food garbage.

$48 \%$ respondents chose poor knowledge of garbage classification by people or poor propaganda by government. $30 \%$ respondents chose the poor hardware facilities. $22 \%$ respondents chose poor public awareness of environmental protection.

$56 \%$ respondents chose damaged city's appearance. 24\% respondents chose air pollution (methane). 65\% respondents chose bacterial reproduction and infectious diseases. 22\% respondents chose serious water \& soil pollution.

$30 \%$ respondents chose poor laws and regulations. 26\% respondents chose poor implemention by government. $20 \%$ respondents chose poor consciousness by citizens. $24 \%$ respondents chose poor propaganda.

$50 \%$ respondents believed that the government should strengthen propaganda and supervision. $24 \%$ think that social organizations should hold lectures. $14 \%$ respondents think that famous media should strengthen propaganda. $12 \%$ respondents think that individuals should teach themselves more knowledge about environmental protection.

Question 1 to question 6 in Table 1 are extracted from the survey in general people. Main observations figured out from these answers include: (1) General residents pay little attention to garbage related issues usually. Public concern about kitchen waste related problem is poor. Few people have heard of the interim management of food waste disposal by government in Hangzhou. Most of them don't know the contents in the document. It indicates that the policy made by government has not been informed to the general people adequately. More propaganda work needs to be done. (2) Modern media is the most important way for the public to receive propaganda. Nearly half of the people received relevant knowledge via television, internet or radio. (3) General people have the potential willingness to cooperate with garbage classification. Although many people didn't carry out the classification of kitchen waste, $23 \%$ of them believe that they will do so if convenient hardware facilities are available.

Question 7 to question 14 in Table 1 is extracted from the survey in catering industry related people. Main observations figured out from these answers include: (1) as to the food industry in Hangzhou, attention to food waste's recycling is seriously lack. Only 129 of the 966 catering workers in this survey believe that food waste can be divided into two kinds, the recyclable and the non-recyclable, and think it is necessary to carry out classification. This number accounts for only $13 \%$ of the respondents. (2) The awareness of environmental protection for catering employees is closely related to their certain work position. This observation is out of expectation. Managers are more aware of issues of classification and recycling of kitchen waste than the managed. The people who think kitchen waste could and should be classified are usually found to be managers. On the contrary, the 
one who think it is unnecessary to do so are usually found to be the managed. The key problem behind the phenomenon seems to be who should do the tedious thing. (3) The frequency of garbage disposal in the catering industry in Hangzhou meets required standard, but the classification of garbage is not done well. Most of the restaurants deal with garbage once a day. In general, restaurants that produce larger quantity of garbage deal with them more frequently. While, only $6 \%$ of the respondents use trash bins with filter membrane to separate different kitchen waste. These observations indicate that the classification of food waste in the catering industry in Hangzhou is not optimistic yet. And much more work need to be done. (4) Most people think that the government should do more to improve the treatment of kitchen waste in Hangzhou. Nearly half of the managers in the catering industry think that the government's supervision is not enough currently and more stringent management with penalties is necessary.

\section{Conclusions}

As discussed above, some points could be extracted from the investigations in general citizens in Hangzhou. Firstly, public attention to food waste issues is not enough. Due to the lack of extensive propaganda and guidance, people didn't realize the severe challenges of food waste. Moreover, the degree of attention to kitchen waste is related to people's age, occupation and so on. Therefore, it is necessary to strengthen propaganda in certain populations in future. Secondly, collection and disposal of kitchen waste in Hangzhou is not standardized currently. Collection, transportation and disposal of kitchen waste in Hangzhou are not standardized yet. Thirdly, the top-level design for food waste management measures by the government needs to be optimized. And the implementation and supervision needs to be strengthened. Fourthly, is the garbage classification has not been widely implemented. And more practical measures are required to promote the action.

Because of the high population density and the rapidly developing economy, many problems faced by China are not so easy to solve. The problems observed in Hangzhou might exist in most cities in China currently. If the government of Hangzhou tries to find effective measures for classification and disposal of kitchen waste, it will provide important templates for the cities all over the country.

\section{Acknowledgement}

This research was financially supported by Zhejiang provincial philosophy and social sciences plan Construction, evaluation and optimization of Zhejiang provincial municipal solid waste's classification model.

\section{References}

[1] J.J. Lay, K.S. Fan, C.H. Ku. Influence of chemical nature of organic wastes on the conversion to hydrogen by heat ahock digested aludge. International journal of hydrogen energy, 28(2003)1361-1367.

[2] K. Schanesa, K. Dobernig, B. Gözeta, Food waste matters - A systematic review of household food waste practices and their policy implications, Journal of Cleaner Production. 182(2018)978-991

[3] F. Chen, Z. Luo, Y. Yang, G.J. Liu, J. Ma, Enhancing municipal solid waste recycling through reorganizing waste pickers: A case study in Nanjing, China, Waste Manag Res. 2018. doi: 10.1177/0734242X18766216.

[4] J.E. Rutkowski, E.W. Rutkowski, Expanding worldwide urban solid waste recycling: The Brazilian social technology in waste picker’s inclusion, Waste Manag Res. 33(2015)1084-1093.

[5] Y.C. Chen, Effects of urbanization on municipal solid waste composition, Waste Manag. 2018. doi: 10.1016/j.wasman.2018.04.017. 